This is a self-archived version of an original article. This version may differ from the original in pagination and typographic details.

Author(s): Kokkoniemi, Mikko; Isomöttönen, Ville

Title: Project Education and Adams' Theory of Equity

Year: 2020

Version: Accepted version (Final draft)

Copyright: (C) IEEE, 2020

Rights: In Copyright

Rights url: http://rightsstatements.org/page//nC/1.0/?language=en

Please cite the original version:

Kokkoniemi, M., \& Isomöttönen, V. (2020). Project Education and Adams' Theory of Equity. In FIE 2020 : Proceedings of the 50th IEEE Frontiers in Education Conference. IEEE. Conference proceedings : Frontiers in Education Conference.

https://doi.org/10.1109/FIE44824.2020.9274126 


\section{Project Education and Adams' Theory of Equity}

\author{
$1^{\text {st }}$ Mikko Kokkoniemi \\ Faculty of Information Technology \\ University of Jyväskylä \\ Jyväskylä, Finland \\ mikko@kokkoniemi.com
}

\author{
$2^{\text {nd }}$ Ville Isomöttönen \\ Faculty of Information Technology \\ University of Jyväskylä \\ Jyväskylä, Finland \\ ville.isomottonen@jyu.fi
}

\begin{abstract}
This work-in-progress paper in research category is concerned with students' perceptions of justice in software engineering group projects. Taking a directed content analysis approach, the aim is to analyze the relevance of Adams' theory of Equity for small-group project education. The analysis was applied to the data collected from a third-year project course in which students encounter an open-ended group assignment. The results indicate that the theory can serve as a useful framework that helps teachers to identify justice-related issues in project courses. On the other hand, it was concluded that special carefulness is advisable considering the simplicity of the theory.

Index Terms-justice, group work, project-based learning
\end{abstract}

\section{INTRODUCTION}

Students are typically rewarded equally in small-group project education despite the possible differences in total effort, which highlights the importance of the justice perspective in such education. This is especially stressed when the environment is not strictly moderated and there is a need for self-organization in a group. Yet existing justice theories do not seem to populate literature on project-based learning. Higher education literature has rather documented the fear of unpredictability and lack of control for justice as key issues from students' perspective [1]-[3]. The topic of justice is also present when issues such as social loafing are discussed [4]. In computing studies, addressing group work situations is typically referred to in conjunction with peer assessment (e.g., [5]) and grouping strategies (e.g., [6]).

This study is concerned with students' perceptions of justice in software engineering group projects. Taking a directed qualitative content analysis approach [7], the relevance of Adams' Theory of Equity [8] is investigated in a small-group setting. According to the theory, students should be satisfied if they perceive a balance between their input for and reward of the group work. The analysis was applied to data collected in an undergraduate project course, in which students encounter an open-ended assignment. The aim of this study is to inform teachers about the usefulness of the theory as a framework for addressing justice when operating a project course.

\section{AdAMS' THEORY OF EQUiTy}

J. Stacy Adams developed the theory of equity at early 1960s while working in a social science program concerning wages and productivity research at General Electric Company [8], [9]. He noted that the theory is based upon Festinger's theory of cognitive dissonance [10], and is actually a special case of it. George Homans' pioneering ideas of distributive justice [11] had also a major impact on the theory.

In the original paper, Adams [8] stated that three theoretical variables are crucial to apprehending the essence of the theory. The first is the chosen referent used in evaluating the equity; ergo, a comparison other. This can for example be a group member or even oneself in a different role or situation. Other two are the inputs that one invests in the exchange and the outcomes one receives in return. A typical input can be an education, skill, or the effort by which individual contributes to the exchange, whereas the outcome can be, e.g., a course grade, pay, or some more intrinsic reward. Inequity exists when one's perceived inputs and outcomes are psychologically in a different relation to what is perceived of the chosen referent. This can happen if inputs or outcomes are not fully recognized by either party of the exchange or their relevance is perceived differently. (see, [8])

Furthermore, the theory suggests that when an imbalance in the exchange is beneficial to an individual, the perceived inequity may manifest itself as guilt [12]. If the imbalance is disadvantageous instead, it may arouse feelings of anger [12]. Either way, one tends to minimize the felt distress by leaving the field or more likely by altering inputs, outcomes, or the chosen referent [8]. Adams proposed [8] that the one in distress may also cognitively distort the inputs or outcomes of oneself or the chosen referent. An example given by Adams is that one cognitively diminishes one's own inputs if underrewarded. The greater the perceived inequity is, the more distress is felt [8]. Table I may prove useful for comprehending the amount of perceived inequity when the outcome to input ratios differ: for example, when an employee considers a salary

TABLE I

A MODIFICATION OF ADAMS' ILLUSTRATION [8] OF THE AMOUNT OF INEQUITY IN RELATION TO THE CHOSEN REFERENT

\begin{tabular}{|c|c|c|c|c|c|c|}
\hline \multirow{2}{*}{\multicolumn{2}{|c|}{ Self }} & \multicolumn{5}{|c|}{ Referent } \\
\hline & & \multirow{2}{*}{$\begin{array}{l}\text { low } \\
\text { high }\end{array}$} & \multirow{2}{*}{$\begin{array}{c}\text { high } \\
\text { low }\end{array}$} & \multirow{2}{*}{$\begin{array}{l}\text { low } \\
\text { low }\end{array}$} & \multirow{2}{*}{$\begin{array}{l}\text { high } \\
\text { high }\end{array}$} & \multirow{2}{*}{$\begin{array}{l}\text { input } \\
\text { outcome }\end{array}$} \\
\hline input & outcome & & & & & \\
\hline low & high & - & much & some & some & \\
\hline high & low & much & - & some & some & \\
\hline low & low & some & some & - & - & \\
\hline high & high & some & some & - & - & \\
\hline
\end{tabular}


to be low in respect of high inputs and also knows a colleague to be better paid for lower inputs, the perceived imbalance generates 'much' inequity. Suggested by the theory, the felt distress can affect the quality or amount of contributed work in a group project, or even cause one to drop out.

Adams envisaged that people might have different norms for the proper distribution of rewards, and that it is necessary to know something of the values and norms to which the culture is associated [8]. What Adams did not take into account is that individuals may not be equally sensitive to equity. Long after the Adams' original paper, Huseman et al. [13] presented the idea of individual differences in equity sensitivity as an extension to Adams' theory. This extension proposed three categories: benevolents, equity sensitives, and entitleds. Benevolents think more of giving than receiving, and tolerate the condition in which the chosen referent has bigger outcome to input ratio than themselves. Equity sensitives represent a traditional equity theory model, and prefer the situation in which outcome to input ratios do not differ between a chosen referent and themselves. Lastly, entitleds have high thresholds for feeling indebted and prefer that their outcome to input ratios are bigger than that of the referents.

\section{THE STUDY}

The study context is an undergraduate project course where groups are formed in a way that students in a group have not previously worked together. The practical objective is to develop a working software within a 12-week timeline. Students have to contribute a minimum of 100 work hours. A mid-course intervention session, addressing potential ingroup justice- and team dynamics issues, is arranged for each group. This is facilitated by a course supervisor presenting various exercises that intend to encourage the group to process sensitive matters. The course is graded using a pass/fail scale, which allows sensitive group discussions to occur without a competitive atmosphere; hence, students are rewarded equally. In line with the Adams' theory [8], equal rewards may introduce a perception of inequity if the inputs vary among group members, which makes this course an applicable setting to test the theory. The course setting is detailed in [14].

Two case groups were reviewed in the light of the Adams' theory because more groups would have not fitted in the workin-progress paper. To be able to initially test the theory, the groups were ad-hoc selected among those in which issues with justice could be identified through screening of the learning reports data collected over the past six years. During this time the course setting has remained unchanged, and the consents to use the data have been acquired during yearly courses. In these reports, students are asked to consider their position in projects in multiple ways, including equity. The two authors reviewed one case each, after which the analyses were discussed to evaluate the usefulness of the theory. As this preliminary work focused on two cases, participant anonymity was solidified by changing the names and not including quotations.

Finally, the analyses demonstrated are not judgmental but conceptual; each group is a temporary, emergent, composition and individual statuses are influenced by a multitude of aspects not taken into account in the scope of our preliminary analyses (e.g., self-efficacy).

\section{A. Case A}

The group consists of four members, each providing inputs at a different level, which apparently seems to generate some distress, as two of the group members feel guilt for their low contributions and one is clearly disappointed for being underrewarded.

In this group, an individual member may have more than one referent chosen. Naturally all the members compare their contribution to each other and thus choose one another as a referent, but Glen is on the course to gain an experience comparable to a starting position in industry and therefore plays a role of a self-selected referent in a hypothetical trainee position. Similarly, Lee chooses self in a previous group work setting as a reference to which the contributed inputs are compared.

1) Glen's considerations: The chosen referent may have provoked Glen to have high expectations for the rest of the group and to be a bit disappointed since the course did not match working in a real software engineering team in a company. Yet this may also partly be a result of having higher inputs compared to the other group members and hence feeling more distress than others, as the theory suggests. Glen expects not only to receive a 'pass' grade but also valuable experience and a high quality software, which would demonstrate the skills of the authors. Thus, the expectations for the outcomes were higher than those of the other members.

Although the team has project management issues since no one clearly takes the role of a manager, Glen bears most of the responsibility and is regarded as the manager of the group despite Glen sees the managerial role as a burden. Indeed, managing the project is seen as a considerable input along with the high effort regarding coding the software, and Glen acts in line with the theory, aiming to correct the perceived imbalance. Thus, Glen ends up avoiding the leadership, which had a negative effect in the progress and the atmosphere. This is however not enough to correct the perceived inequity, so later in the project Glen regulates contributing to the group work, dedicating the rest of the course to developing knowhow and skill instead of participating in the project.

Glen's reactions to inequity are in line with how the theory predicts them to be. Concluded that Glen's inputs are high and outcomes low, Table I shows that Glen perceives much inequity against the imagined work-place referent, who might be benefiting by the junior position more than the other side of the exchange. Since Glen perceives other group members to have both low inputs and low outcomes, at least some inequity is additionally perceived against them.

2) Jordan's considerations: Jordan does not feel distress as strongly as Glen, but is still worried about contributing to the project in an adequate manner. Thus, Jordan perceives being a bit overrewarded in relation to Glen, but at the same time slightly underrewarded in relation to Lee, who seems 
to underperform. However, Jordan has a notable tendency to accept the inequity in relation to Lee, who has a good reason for the bad performance. Adams noted that in some cultures outcomes (e.g., salary) are based on the need of the individual rather than on contributions [8], which can explain why Jordan can handle the situation in this manner. However, this should be explored further and may for example be due to the Jordan's empathy for Lee. It appears that Jordan reacts to the guilt about the perceived inequity and tries to be more involved in the project towards the end of the course.

3) Lee's considerations: Lee admits doing less than others, but emphasizes the inputs in a different way and attributes a special importance to creating an atmosphere, hence underlining the value of entertaining others. In this way, Lee moderately distorts the significance of the inputs, thus dealing cognitively with the perceived imbalance of efforts. Additionally, Lee justifies the bad performance with a situation outside the project.

4) Dorian's considerations: Interestingly, Dorian has quite deviant experiences. Whereas other members feel either underor overrewarded and thus perceive some inequity, Dorian keeps the positive tone all the way from start to end, focusing on the depiction of the course events, and does not really recognize issues with equity. However, Dorian reveals in a quick side note that it seemed that sometimes not everyone was equally committed to the project, but immediately states that this was not a real problem since it got better towards the end of the project.

5) Summary of Case A: The atmosphere of the group clearly affects the individual inputs and the perceived inequity, since it is described as being reserved despite there was some attempt to ease the tension with humor. Problems were not discussed inside the group nor help asked; lack of proactivity and trust characterizes the group. One could, however, argue whether the atmosphere itself should be considered either an input or an outcome. Most probably it should be interpreted as a factor implicitly affecting equity evaluations. Furthermore, classifying members according to the equity sensitivity is not straightforward. Glen has high expectations for the rest of the group and might be considered equity sensitive, whereas Jordan is constantly worried of doing too little and might be regarded as benevolent. The sensitivity level of others are not as apparent, but Lee gives a small hint of being entitled to a lower commitment because of a situation outside the project. Each member appreciated the intervention session in the middle of the course, which seems to be an efficient method to address the issues of justice and change the direction of the project (evaluation under review).

\section{B. Case B}

Also Case B consisted of four members.

1) Dale's considerations: Echoing the theory, Dale identifies an imbalance with an experience of guilt. This experience is based on the considerations of the amount of concrete outcomes. On the other hand, there was a personal learning curve that had to be tackled-an effort that can also be seen as an input in the light of the theory. The selection of referents is rather directly differentiated based on the amount of experience among the group members. As a measure to manage distress (see Section II), self with more experience is identified as a hypothetical referent. Furthermore, helpfulness of the experienced members is acknowledged and valued; this helpfulness is yet another aspect that can be seen as the input in the light of the theory. Some passages suggest that Dale is kind of fixing the position in which one receives support. Such nuances are interpreted to indicate a tendency toward an unrecognized entitled position because of the lacking experience. Here, the theory (see Section II) altogether helps us to hypothesize that an alternation between experiences of guilt and being entitled may arise on the part of less experienced students in groups where initial skill levels differ.

2) Ashley's considerations: Ashley appears benevolent based on efforts put into exchange in the form of supporting others, on top of personal contributions acknowledged by the group. A kind of imposed equity sensitiveness finally emerges out of disappointment (cf. anger mentioned in the theory), along with the observation of little change in the group situation that was considered to demonstrate imbalances in the exchange. An alternation between willingness to understand different backgrounds and situations affecting inputs (cf. benevolent) and stress about imbalance between inputs (equity sensitiveness) can be identified. The analysis extends beyond the project setting as Ashley identifies lack of authority over the project situation. This extension, or coping with distress, also included an identification of insufficient course prerequisites, in which the referent can be interpreted to be self in a more favorable curricular situation. Provided as a reflection, Ashley would demand 'initiative' in asking help and taking up tasks, which in our interpretation describes an input by which experiences of reciprocity can be enhanced on the part of advanced students when skill levels differ.

3) Marion's considerations: A learning curve that had to be tackled is reported, which, similar to the analyses above, can be identified as an input in the light of the theory. Tackling the learning curve appears to consume lots of resources but yet an imbalance of the inputs regarding the amount of work is recognized, and thus a conflict between experiences of guilt and being entitled to the situation because of the learning curve is slightly indicated. Help received is valued and justice is observed to be improved toward the end, indicating a change in personal inputs. The selection of referents is differentiated according to amount of experience in the group, those with more experience providing more contributions. The referent is also a hypothetical self with more experience, envisaged to provide a more favorable setting to start a project. Distress out of the conflict described is also linked with a situation outside the project (similar to Lee in Case A), when the referent can be interpreted to be self in a less complicated situation. Echoing the theory, reaction to imbalance includes increasing one's inputs (cf. improved justice above), which in the end engenders educational satisfaction with the project. In a certain sense, a conflict between the experiences of guilt and being entitled 
may transform into a situation in which equity sensitivity becomes possible - a hypothesis for subsequent research.

4) Noel's considerations: Noel considerations are anchored in high personal input. The obvious referents are the other members according to their efforts, and imbalances are recognized. Also here one can identify an alternation between benevolence and equity sensitiveness. Distress arising from perceived imbalance is managed in several ways. One is comparison to working life in which the situation of imbalance is considered to be more severe compared to an educational setting. Other way around, under perceived imbalance, personal professional growth available by the project is emphasized. For Noel, honest discussion on group dynamics can be seen to have offered experiences of equity, as this was considered to provide education beyond the project. In sum, coping with distress gives rise to the referent being self in and preparing for working life. Moreover, controlling one's inputs (cf. Glen in case A) by taking only a consultative role in the end of the project can be interpreted as an alteration to one's inputs and a strategy for not increasing perceived imbalance.

5) Summary of Case B: The differences in pre-experience relevant to the project creates a challenging starting point for the group, and how this condition begins to evolve is present in the evaluations of (in)equity. 'Inputs' included concrete efforts and outcomes, learning, help, and initiative. The group members evaluate and emphasize inputs differently to some extent (see Section II). An implication is that students could be asked to reflect on the nature of these inputs early on, to help groups to develop toward a fruitful learning condition. Reflecting the theory, reactions to perceived imbalance included both increasing and limiting of inputs. Several ways of managing distress were identified, with the referent being a hypothetical self envisaged in another, more favorable setting. Such considerations might be seen as cognitive "way out(s)" that are comparable to the cognitive distortion of referents when imbalance is perceived (see Section II). Similar to what is speculated about atmosphere in Case A, a factor potentially affecting evaluations of inequity in Case B is problematic communication that was occasionally referred to. Future research should clarify whether within-group communication stands as an input or a setting implicitly affecting the perceptions of (im)balance.

\section{Discussion}

The study examined two undergraduate case groups which had apparent equity issues. Students' learning reports were analyzed with a directed approach [7] in the light of the Adams' theory of equity, and the factors and consequences of inequity were identified. We are of the opinion that the Adams' theory proved to be a valuable measure to classify and conceptualize justice-related team dynamics factors.

It will be interesting to extend the analysis and study how central role the referent plays in determining the perception of equity in group projects. Another interesting topic is the actual referent selection. Questions about how typical it is that students compare their situation to a hypothetical situation at work or some other project environment are essential, as it seems that the comparison target may affect the expectations a student has of the rest of the group.

Both cognitive and behavioral coping strategies for dealing with inequity were identified. Altering inputs (see Section II) was most evident in the considerations of Glen (Case A) and Noel (Case B), who avoided their inputs growing unsustainably large in comparison with others. Others had more clearly cognitive means (cf., cognitive distorting in Section II). For example, those who underperformed might have acknowledged their low inputs but concurrently sought to find their own merits or justified the situation because of the low skill level. Yet, the theory does not detail cognitive coping strategies other than cognitive distorting, which raises a question if those should be further investigated in the context of equity.

Since the Adams' theory was deemed helpful for conceptualizing inequity issues, it is proposed to be used in group interventions. Such an intervention would make a group aware of the individual differences regarding the evaluation of the significance of varying inputs and sensitivities to inequity. Currently, we observed that inequity sensitivity is difficult to interpret, and we discussed it as a dynamic matter. While it is obviously a good thing that in many project courses fairness can be achieved at the end by giving a grade or credits equivalent to the individual's contribution, this does not prevent students from reacting to inequity before the end of the course. As for the present target course, this would complement currently well-working intervention strategies (evaluated in another study).

Although the theory appears to be useful, our observation was that the amount of a distress does not necessarily result only from the imbalance in the exchange, as the theory suggests, but also from situational factors. For example, when the imbalance originates from the referent being busy instead of plain laziness or social loafing, one may be able to tolerate it. On the other hand, social loafing may be difficult to bear even in small portions. These aspects provide a setting for discussion for project course teachers who unavoidably need to consider whether and how significantly they intervene in group situations.

\section{REFERENCES}

[1] P. J. Hinds, K. M. Carley, D. Krackhardt, and D. Wholey, "Choosing work group members: Balancing similarity, competence, and familiarity," Organizational Behavior and Human Decision Processes, vol. 81, no. 2, pp. 226-251, 2000. [Online]. Available: https://doi.org/10.1006/obhd.1999.2875

[2] P. Strauss, A. U, and S. Young, "i know the type of people i work well with': Student anxiety in multicultural group projects," Studies in Higher Education, vol. 36, no. 7, pp. 815-829, 2011. [Online]. Available: https://doi.org/10.1080/03075079.2010.488720

[3] N. Yorra, "Optimizing group learning: A phenomenological study exploring the experiences of senior business students at a major research university," Ph.D. dissertation, Northeastern University, Boston, Massachusetts, 2012.

[4] L. Riebe, A. Girardi, and C. Whitsed, "A systematic literature review of teamwork pedagogy in higher education," Small Group Research, vol. 47, no. 6, pp. 619-664, 2016. [Online]. Available: https://doi.org/10.1177/1046496416665221 
[5] H. H. Smith and D. L. Smarkusky, "Competency matrices for peer assessment of individuals in team projects," in Proceedings of the 6th conference on Information technology education, ser. SIGITE '05. New York, NY: ACM, 2005, pp. 155-162. [Online]. Available: http://doi.acm.org/10.1145/1095714.1095751

[6] Y. G. Sahin, "A team building model for software engineering courses term projects," Computers \& Education, vol. 56, no. 3, pp. 916-922, 2011.

[7] H.-F. Hsieh and S. E. Shannon, "Three approaches to qualitative content analysis," Qual Health Res, vol. 15, no. 9, pp. 1277-1288, Nov. 2005. [Online]. Available: http://www.ncbi.nlm.nih.gov/pubmed/16204405

[8] J. S. Adams, "Towards an understanding of inequity." The Journal of Abnormal and Social Psychology, vol. 67, no. 5, p. 422, 1963.

[9] J. B. Miner, Organizational Behavior: Essential theories of motivation and leadership. one. ME Sharpe, 2005, vol. 1.

[10] L. Festinger, A theory of cognitive dissonance. Stanford university press, 1962, vol. 2 .
[11] G. C. Homans, "Social behavior: Its elementary forms." 1961.

[12] J. S. Adams, "Inequity in social exchange," ser. Advances in Experimental Social Psychology, L. Berkowitz, Ed. Academic Press, 1965, vol. 2, pp. 267 - 299. [Online]. Available: http://www.sciencedirect.com/science/article/pii/S0065260108601082

[13] R. C. Huseman, J. D. Hatfield, and E. W. Miles, "A new perspective on equity theory: The equity sensitivity construct," Academy of management Review, vol. 12, no. 2, pp. 222-234, 1987.

[14] V. Isomöttönen, M. Daniels, A. Cajander, A. Pears, and R. McDermott, "Searching for global employability: Can students capitalize on enabling learning environments?" ACM Transactions on Computing Education - Special Issue on Global Software Engineering Education, vol. 19, no. 2, pp. 11:1-11:29, Jan. 2019. [Online]. Available: http://doi.acm.org/10.1145/3277568 